\title{
A IMPORTÂNCIA DA DIVERSIDADE DE GÊNERO NOS CONSELHOS DE ADMINISTRAÇÃO PARA A PROMOÇÃO DA RESPONSABILIDADE SOCIAL CORPORATIVA
}

THE IMPORTANCE OF GENDER DIVERSITY ON BOARDS OF DIRECTORS FOR FOSTERING CORPORATE SOCIAL RESPONSIBILITY 


\title{
A IMPORTÂNCIA DA DIVERSIDADE DE GÊNERO NOS CONSELHOS DE ADMINISTRAÇÃO PARA A PROMOÇÃO DA RESPONSABILIDADE SOCIAL CORPORATIVA
}

\author{
THE IMPORTANCE OF GENDER DIVERSITY ON \\ BOARDS OF DIRECTORS FOR FOSTERING \\ CORPORATE SOCIAL RESPONSIBILITY
}
Alexandre di Miceli da Silveira
Fecap - Fundação Escola de Comércio Álvares Penteado
alexandre.miceli@fecap.br
http://lattes.cnpq.br/4773608871754250
https://orcid.org/0000-0002-4864-9429

\section{Angela Rita Franco Donaggio \\ FACAMP - Faculdades de Campinas \\ angela.donaggio@facamp.com.br \\ http://lattes.cnpq.br/1360509413646936}

\begin{abstract}
Resumo: Este artigo analisa o impacto da diversidade de gênero nos conselhos de administração sobre a responsabilidade social corporativa por meio da consolidação de sua literatura. Esta questão é relevante por abordar temas caros aos direitos humanos, tais como o empoderamento feminino e seus impactos para a promoção de um ambiente social mais justo e mais responsável do ponto de vista ambiental. A análise agregada de dezenas de trabalhos empíricos mostra que a maior diversidade de gênero nos conselhos está relacionada a diversos impactos positivos, tais como: melhores indicadores de responsabilidade social corporativa, melhor reputação ética e social, maior conformidade às leis e normas, e melhor qualidade dos relatórios divulgados pelas empresas. A conclusão geral deste trabalho é que a diversidade de gênero na alta gestão deve ser vista como prioridade por dois motivos principais. De um lado, por contribuir diretamente com os Princípios de Empoderamento das Mulheres da ONU. Do outro, por contribuir indiretamente para a promoção dos Princípios do Pacto Global, particularmente para aqueles relacionados ao meio ambiente e ao combate à corrupção.
\end{abstract}

Palavras-chave: Diversidade de Gênero, Conselho de Administração, Responsabilidade Social Corporativa, Princípios de Empoderamento das Mulheres da ONU, Pacto Global da ONU. 


\begin{abstract}
We analyze the impact of board gender diversity on corporate social responsibility through the consolidation of its literature. This subject is relevant because it addresses human rights issues such as women's empowerment and its impacts to the promotion of fairness and sustainability in the business world. Our aggregate analysis of dozens of empirical studies shows that greater gender diversity on boards is related to several positive impacts, such as: higher ratings of corporate social responsibility, better ethical and social reputation, stronger compliance with laws and regulations, and better quality of companies' reports. Our general conclusion is that board gender diversity must be seen as a priority for two main reasons. On the one hand, for directly contributing to the UN Women's Empowerment Principles. On the other hand, for indirectly fostering the Global Compact Principles, particularly those related to the environment and anticorruption practices.
\end{abstract}

Keywords: Gender Diversity, Board of Directors, Corporate Social Responsibility, UN Women's Empowerment Principles, UN Global Compact.

\title{
Introdução
}

A igualdade de gênero é considerada prioridade pela ONU na persecução de uma sociedade mais justa e desenvolvida. Por este motivo, foi instituída a ONU Mulheres em 2010, entidade para a igualdade de gênero e o empoderamento das mulheres. Dentre suas diversas iniciativas ${ }^{1}$, destacam-se os Princípios de Empoderamento das Mulheres, sendo o primeiro deles “estabelecer liderança corporativa sensível à igualdade de gênero, no mais alto nível".2

A ínfima participação de mulheres em cargos de liderança nas empresas é realidade em todo o mundo ${ }^{3}$ e a situação se mostra estagnada em países como o Brasil. ${ }^{4}$ Como resultado, diversas iniciativas têm sido adotadas a fim de aumentar a Diversidade de Gênero nos Conselhos de Administração (“DGC”) das companhias. Algumas dessas iniciativas são voluntárias, enquanto

\footnotetext{
1 Dentre as diversas iniciativas da ONU quanto ao tema, pode-se citar a "Declaração e Plataforma de Ação da IV Conferência Mundial sobre a Mulher Declaração" (1995), o Pacto Global, as Metas do Milênio, "Committee on the Elimination of Discrimination against Women" (CEDAW), os Princípios Orientadores sobre Empresas e Direitos Humanos, e diversos relatórios, como UN Doc. A/ $\mathrm{HRC} / 4 / 35, \mathrm{~A} / \mathrm{HRC} / 8 / 5$ e A/RES/66/288. Esses documentos apresentam a importância do empoderamento das mulheres, da eliminação de estereótipos de gênero e de qualquer forma de discriminação, como a exclusão de certas ocupações, tais como os cargos de liderança e alta gestão, ocupações estas que impactam fortemente a sociedade na qual estão inseridas.

2 THE GLOBAL COMPACT. Women's Empowerment Principles, the UN Global Compact and the Guiding Principles on Business and Human Rights - explanatory note. Disponível em: https://www.unglobalcompact.org/docs/ issues_doc/development/WEPs\%2C_ UNGC\%2C_Guiding_Principles_on_Business_and_Human_Rights_Explanatory_Note.pdf . Acesso em: 29 abr. 2017. Ver também as iniciativas "The Gender Dimension of Business and Human Rights: Introducing the Women's Empowerment Principles - Equality means Business", "Companies Leading the Way", "Companies Leading the Way: Putting the Principles into Practice".

3 Ver THE CORPORATE GENDER GAP REPORT. World Economic Forum, Genebra, 2010, WOMEN MATTER 2013: gender diversity in top management: moving corporate culture, moving boundaries. McKinsey \& Company, 2013, SANDBERG (2013).

4 Com base em pesquisa empírica que analisou mais de 800 companhias listadas durante 15 anos, SILVEIRA et al. (2013) demonstram que a participação de mulheres nos conselhos de administração, diretorias executivas e conselhos fiscais está estagnada.
} 
outras são resultado de ações afirmativas, prática apoiada pela $\mathrm{ONU}^{5}$ e já implantada em diversos países. ${ }^{6}$

Outra evidência do aumento da relevância do tema foi o desenvolvimento de uma linha de pesquisa nos últimos anos dedicada a investigar os impactos da DGC sobre as decisões empresariais e o desempenho das companhias. Os primeiros estudos sobre a DGC se concentraram em seus potenciais benefícios financeiros ${ }^{7}$. Mais recentemente, outros passaram a se concentrar nos benefícios não-financeiros decorrentes do aumento da proporção das mulheres nos cargos de alta gestão.

Nesse sentido, este artigo busca contribuir para essa área de pesquisa, de forma a expandir o chamado "business case" no que se refere à maior DGC das companhias e seus benefícios não econômicos. ${ }^{8}$ Especificamente, este trabalho revisa e consolida a literatura recente de pesquisas empíricas que analisam a relação entre a DGC e o desempenho" de "Responsabilidade Social Corporativa" ("RSC") em diferentes países. ${ }^{10}$

Como se verá adiante, essa literatura mostra que uma maior DGC (concretizada pelo respeito aos direitos humanos e a não discriminação no ambiente de trabalho - dois princípios do Pacto Global), impacta positivamente outros princípios do Pacto, relacionados à proteção ao meio ambiente e a práticas anticorrupção.

Sob uma perspectiva mais ampla, este trabalho procura contribuir para o debate na medida em que mostra que a própria DGC pode atuar como uma via de mão dupla em relação aos Princípios de Empoderamento Feminino e do Pacto Global. Os resultados consolidados apresentados neste artigo também demonstram que a DGC ocasiona outros impactos positivos

5 UN Doc. A/RES/66/288: “237. (...) We support prioritizing measures to promote gender equality and women's empowerment in all spheres of our societies, including the removal of barriers to their full and equal participation in decision-making and management at all levels, and we emphasize the impact of setting specific targets and implementing temporary measures, as appropriate, for substantially increasing the number of women in leadership positions, with the aim of achieving gender parity."

6 A pressão para aumentar a DGC vem não apenas das partes interessadas, mas também dos formuladores de políticas. Desde o exemplo pioneiro da Noruega no início dos anos 2000, mais de uma dúzia de países, incluindo França, Alemanha e Itália, aprovaram legislações para estabelecer quotas para mulheres nos conselhos de administração.

7 Existe uma literatura vasta que examina a relação entre DGC e desempenho financeiro. Os resultados até agora são mistos. Alguns artigos encontram efeitos positivos, tais como Campbell e Mínguez-Vera (2008), Dezsö e Ross (2012), e Terjesen et al. (2015), enquanto outros encontram resultados tanto positivos quanto negativos (Adams e Ferreira, 2009; Matsa and Miller, 2013). Para uma revisão desta literatura, ver Terjesen et al., (2009) e Post e Byron, (2015).

8 É importante enfatizar que, em geral, os desempenhos social e econômico são relacionados. Por exemplo, muitos trabalhos verificaram que companhias que apresentam práticas mais éticas tendem a apresentar efeitos positivos quanto à lucratividade e avaliação de mercado (ex: Fischer e Khoury, 2007; Choi e Jung, 2008; Donker, Poff e Zahir, 2008; e Blazovich e Smith, 2011). Adicionalmente, estudos meta-analíticos concluíram que a RSC contribui para um melhor desempenho financeiro (ex: Wood, 2010; e Lu, Chau, Wang e Pan, 2014). Outros estudos concluíram que a desempenho social corporativo é positivamente associado a resultados importantes, tais como compromisso organizacional (Rayton, Brammer, and Millington, 2015), satisfação dos funcionários (Bauman e Skitka, 2012), e satisfação das partes interessadas (Carroll, 1999).

9 O conceito de desempenho das práticas de RSC abarca questões como: iniciativas de RSC, reputação ética e social, nível de cumprimento das leis e normas, e integridade e transparência de relatórios financeiros e não-financeiros.

10 Neste artigo, será utilizado o termo Responsabilidade Social Corporativa ("RSC") para descrever todas as atividades das empresas que envolvam as partes interessadas, o respeito às leis, normas, direitos humanos e meio ambiente. Segundo a própria ONU, muitos termos surgiram nos últimos anos para descrever o mesmo fenômeno que consiste nas atividades de responsabilidade social e ambiental das empresas, tais como os termos responsabilidade corporativa, cidadania corporativa, sustentabilidade corporativa e responsabilidade social corporativa. Disponível em: https://business.un.org/en/documents/csr . Acesso em 29 abr. 2017. 
do ponto de vista social e ambiental, incluindo o maior respeito às partes interessadas, melhor prestação de contas e outras iniciativas de RSC.

A igualdade de gênero e o empoderamento feminino são imperativos morais de justiça social que independem de justificativas utilitaristas. Apesar disso, muitas companhias e lideranças ainda se orientam apenas por essa ótica. ${ }^{11}$ Também por isso, pretende-se sintetizar as evidências que relacionam uma maior presença de mulheres nos conselhos de administração aos resultados positivos não-financeiros. ${ }^{12}$

Atingir a paridade de gênero nos conselhos de administração é um dos grandes desafios que as companhias devem enfrentar no século XXI. Logo, este artigo busca contribuir com "igualdade entre os gêneros mediante a promoção de estudos da mulher e a utilização dos resultados de estudos e pesquisas sobre gênero em todos os campos, inclusive o econômico, o cientifico e o tecnológico". ${ }^{13}$

O presente trabalho é dividido da seguinte forma. A próxima seção aborda o racional, isto é, as questões que fundamentam a visão de que ter mais mulheres nos conselhos pode levar a melhores decisões do ponto de vista ético e social. A seção 2 explica as métricas utilizadas para se chegar a um constructo complexo e multidimensional de RSC. As seções 3, 4 e 5 apresentam, respectivamente, os resultados de estudos que relacionam a DGC a (i) medidas gerais e específicas de RSC; (ii) reputação ética e social e (iii) conformidade às leis e qualidade de relatórios financeiros e não-financeiros.

\section{Por que maior Diversidade de Gênero nos Conselhos pode levar a um melhor desempenho de Responsabilidade Social Corporativa?}

A literatura ressalta possíveis explicações sobre porque mais mulheres nos âmbitos decisórios poderia levar a um melhor desempenho quanto à RSC, mas é importante destacar que não há consenso na literatura acerca da existência de diferenças permanentes, essenciais ou biologicamente determinadas entre mulheres e homens.

11 Ver SEIERSTAD (2015) e HILLMAN (2015, p. 105), que faz uma crítica importante - e pouco observada - sobre as pesquisas desta linha: "Can or should we expect to find a financial performance result of boardroom diversity? And if we don't, can we argue there is no "business case" for diversity in the boardroom?... Looking for a financial performance relationship could be more difficult due to a lack of understanding of potential biases on the part of analysts, institutional and other investors, not to mention lenders. In other words, could financial performance be negatively biased by these groups 'perception that women in the boardroom will hurt the future prospects of the firm?".

12 Vale destacar três ressalvas. Em primeiro lugar, embora a grande maioria dos artigos pesquisados tenham encontrado um impacto positivo da DGC no desempenho de RSC das empresas, alguns trabalhos encontraram relações nulas ou negativas (e.g. RodriguezDominguez et al., 2009, Lorenzo e Garcia-Sánchez, 2010, Rao et al., 2012). Em segundo lugar, como ocorre em todos os campos, os artigos publicados tendem a ser enviesados para aqueles que encontraram resultados estatisticamente significativos (estudos que não encontraram resultados significativos são menos propensos a serem aceitos para publicação). Terceiro, considerando que a DGC não é exógena, a identificação de causalidade torna-se muito difícil e os estudos não são conclusivos quanto a inferência causal da maior proporção de DGC para melhores resultados sociais. Como resultado, embora a maioria dos estudos tenha tentado minimizar as preocupações quanto à endogeneidade (recorrendo a diferentes especificações econométricas, verificações de robustez, variáveis alternativas, etc.), os resultados devem ser interpretados como associações positivas entre DGC e desempenho social.

13 Conforme item 175, "e" da Declaração e Plataforma de Ação da IV Conferência Mundial sobre a Mulher, Pequim, 1995. 
Também não há consenso sobre qual fator - dentre biológicos, psicológicos e culturais seria determinante ou teria maior impacto na definição das características e atitudes individuais, provenientes da interação entre esses fatores e do contexto social. ${ }^{14}$

Considerando todas as ressalvas, foram elencadas e classificadas algumas das características dos âmbitos individual e social que podem estar relacionadas aos impactos positivos da DGC no desempenho de RSC.

\subsection{Características de âmbito individual}

Diversas pesquisas investigam características de âmbito individual geralmente associadas às mulheres que podem ter relação com questões biológicas e psicológicas. Quanto ao aspecto biológico, pesquisas na área de neurociência tais como KANSAKU et al., 2000 verificam que as mulheres usam os dois lados do cérebro em seu processo decisório. Segundo estudos de DAILY et al. (2000), ROSE (2007) e HILLMAN (2015), isso sugere que o processo decisório das mulheres tenderia a abordar um maior espectro de implicações para diversas partes interessadas. Dessa forma, mais mulheres nos conselhos de administração pode levar a um melhor desempenho não-financeiro em virtude de as mulheres serem mais propensas a considerar um maior espectro de interesses em seu processo decisório, tais como os impactos de suas decisões nos stakeholders e no meio-ambiente.

Quanto ao aspecto psicológico, ressalta-se a importância da empatia ${ }^{15}$ para justificar o porquê mais mulheres nos conselhos impacta positivamente iniciativas de RSC. A literatura de psicologia demonstra com diversas evidências, tais como as abordadas por EISENBERG e MILLER (1987) e STURMER et al. (2005), que a empatia não é apenas um "sentimento", mas também um preditor da propensão de alguém oferecer auxílio a outra pessoa quando confrontado com um pedido real de ajuda. Além disso, HATCH e STEPHEN (2015) também mostram fortes evidências de que as mulheres exibem níveis médios de identidade moral internalizada ${ }^{16}$ mais altos do que os apresentados pelos homens. O trabalho de ADAMS e FUNK (2012) mostra que as mulheres enfatizam mais valores transcendentes do que os homens, enquanto GROYSBERG E BELL (2013) mostram que as mulheres demonstram maior interesse em filantropia e serviços à comunidade. Já MARQUIS e LEE (2013) apresentam evidências que as mulheres contribuem mais para caridade.

Considerando os resultados dessas pesquisas, os maiores níveis de empatia e de

\footnotetext{
14 Por exemplo, as características do nível social podem refletir sobre as características do nível individual. Como resultado, os estereótipos (aqui elencados como características atribuídas no nível social) podem influenciar os comportamentos individuais, criando ciclos que resultam em profecias auto-realizáveis.

15 Sturmer et al. (2005) define empathy as the emotional response, including feelings of compassion and concern, in order to help people in need.

16 A medida em que uma pessoa percebe um conjunto de traços morais como sendo profundamente enraizados em seu autoconceito.
} 
identidade moral internalizada tenderiam a levar as mulheres a apresentarem uma maior sensibilidade a práticas de RSC e a políticas ambientais, conforme afirmam os estudos de NIELSEN e HUSE (2010), DIAMANTOPOULOS et al., (2003), MAINIERI et al., (1997) e DAVIDSON e FREUDENBURG (1996). Ainda, segundo ZHANG et al. (2012), as mulheres se preocupariam mais com as necessidades dos stakeholders, dando força ao argumento de que mais mulheres nos conselhos leva a melhores resultados não-financeiros.

\subsection{Características de âmbito social}

As características de âmbito social são aquelas relacionadas ao que a sociedade considera como sendo "desejáveis" para serem apresentadas por mulheres e homens, características tidas por femininas ou masculinas. Estudos de KOHLBERG (1981) mostram que a socialização de gênero ocorrida na infância tenderia a levar às diferenças percebidas entre as atitudes de homens e mulheres. Nesse sentido, GILLIGAN (1982) afirma que tais características são consequência de um processo de socialização de gênero instigado durante a infância na relação entre pais e filhos. Além disso, também são resultado das diferentes formas de socialização de mulheres e homens, de acordo com LA TAILLE (2002). Assim, conforme mostra DAWSON (1997), mulheres e homens aprendem a desempenhar diferentes papéis em virtude de seu sexo, apresentando valores e preocupações que formam sua personalidade feminina ou masculina na infância.

Com o passar do tempo, conforme GILLIGAN (1982), homens e mulheres passam a ser associados, respectivamente, a éticas diferentes: a ética da justiça e a ética do cuidado, respectivamente. Essa diferenciação pode ser responsável pelo fato das mulheres apresentarem reações mais fortes de cuidado e empatia do que os homens.

Os papéis geralmente atribuídos a cada gênero ("gender roles") envolvem dois tipos de julgamento ou crença, de acordo com EAGLY (2009): um descritivo (ex: a sociedade determina quais são as características "típicas" de cada gênero) e um prescritivo (ex: a sociedade indica quais são as características admiráveis a serem apresentadas por cada gênero em uma cultura específica). Conforme WOOD e EAGLY (2009), essas crenças ou julgamentos podem atuar tanto como normas sociais (enraizadas nas expectativas dos outros) quanto como disposições pessoais (enraizadas nas identidades individuais de gênero). ${ }^{17}$

A construção de gênero está relacionada aos estereótipos de gênero que são generalizações baseadas no sexo que sugerem quais características devem ser apresentadas por um grupo inteiro. ${ }^{18}$ Assim, os indivíduos, a sociedade e todo tipo de organização tendem

17 Essas crenças culturais, em conjunto com seu enfoque cognitivo, mentalidade e visão de mundo, são determinantes importantes de como os gestores administram suas empresas (GALASKIEWICZ, 1991).

18 Pesquisas recentes como a de BIEL et al. (2017) mostram como os estereótipos de gênero começam a interferir na percepção das meninas em idades tão tenras como 5 a 6 anos de idade, que acabam por influenciar os interesses das meninas. Sobre como estereótipos de gênero prejudicam as mulheres na área das ciências e na liderança, ver RIDGEWAY (2009) e REUBEN et al. (2014, 2012). 
a criar expectativas quanto a características e comportamentos a serem apresentados por mulheres e homens. ${ }^{19}$ Um exemplo de crença baseada em estereótipos de gênero é a pressão consideravelmente maior que as mulheres sentem para agir de forma mais cuidadosa e sensível do que os homens, especialmente em situações de dilema ou conflito, conforme apresentam MASON e MUDRACK (1996).

Como resultado, as mulheres tendem a sentir uma maior responsabilidade de: utilizar a ética do cuidado (ex: buscar o bem-estar dos outros e evitar causar mal), conforme assevera GILLIGAN (1982); criar e manter relações recíprocas e sustentáveis, de acordo com SLOTE (2007); e serem guiadas a buscar um fim comum em suas ações, conforme CARLSON (1972).

Os argumentos da literatura da psicologia ganham cada vez mais força com as pesquisas empíricas recentes. Diversas pesquisas mostram que as mulheres: i) são mais alinhadas aos interesses dos stakeholders (BEUTEL e MARINI, 1995, e KODINSKY et al., 2010); ii) tendem a adotar atitudes éticas mais restritas e a realizar mais julgamentos éticos no ambiente de trabalho (FERRELL e SKINNER, 1988; AKAAH, 1989; BERNARDI e ARNOLD, 1997; WEEKS et al. 1999; LOE et al., 2000; VALENTINE e RITTENBURG, 2004; SIMGA-MUGAN et al. 2005; LUND, 2008; IBRAHIM e ANGELIDIS, 2009); iii) têm uma maior conexão com princípios éticos, apresentando maior adesão a eles (ISIDRO e SOBRAL, 2015); são mais propensas a usar seu poder na organização para endereçar questões relacionadas à responsabilidade social (ARLOW, 1991; JAFFEE e HYDE, 2000; BACKHAUS et al., 2002; O'FALLON e BUTTERFIELD, 2005; ADAMS e FUNK, 2012); v) apresentam uma maior probabilidade de se posicionar contra comportamentos antiéticos (MIETHE e ROTHSCHILD, 1994, VERMEIR e BAN KENHOVE, 2008) e de se tornarem responsáveis por canais de denúncia ("whistleblowers") (ROTHSCHILD e MIETHE, 1999). ${ }^{20}$

As pesquisas que verificam diferenças no estilo de liderança também mostram a influência dos estereótipos de gênero: mulheres são consideradas mais participativas e democráticas (MASON e MUDRACK, 1996; BEN-AMAR et al., 2015; RUDMAN e GLICK, 2001; EAGLY et al., 2003; EAGLY e JOHNSON, 1990), bem como mais colaborativas que os homens (KONRAD et al., 2008). A teoria de liderança do papel social (EAGLY e CARLI, 2007; EAGLY e JOHNSON, 1990; EAGLY et al., 1995), por exemplo, descreve que as líderes mulheres têm maior probabilidade de se preocupar com pessoas e cuidar de seu bem-estar, enquanto líderes homens têm maior probabilidade de serem guiados por metas financeiras, tendo como foco a persecução de conquistas pessoais (CARLSON, 1972).

Adicionalmente, os estereótipos de gênero podem levar a diferentes expectativas

19 Gêneros diferentes, portanto, respondem a diferentes normas, atitudes, crenças e perspectivas (PELLED et al. 1999).

20 Além disso, meta-análises apoiam esses resultados por apresentarem evidências pequenas, mas consistentes, de diferenças entre homens e mulheres quanto à orientação moral (JAFFEE e HYDE, 2000) e atitudes éticas (BORKOWSKI e UGRAS, 1998). 
sobre os papéis de homens e mulheres no conselho de administração. ${ }^{21}$ Muitas pesquisas apresentam evidências empíricas sobre essa questão. PETERSON e PHILPOT (2007) mostram que há maior probabilidade de mulheres participarem do comitê de relações públicas, por exemplo. BILIMORIA e PIDERIT (1994), SHRADER et al. (1997), WILLIAMS (2003) e ZELECHOWSKI e BILIMORIA (2006) mostram que há uma maior probabilidade de mulheres atuarem em áreas de RSC e de se sentirem mais confortáveis com iniciativas comunitárias. ${ }^{22} \mathrm{De}$ forma complementar, BETZ et al. (1989) e BERNARDI e ARNOLD (1997) mostram evidências de que os homens se sentem mais confortáveis com atividades lucrativas. Como resultado, é possível que mulheres sejam nomeadas para os conselhos em função de um estereótipo de que mulheres são mais sensíveis, conforme afirmam BURGESS e THARENOU (2002), tornandose então uma profecia autorrealizável.

De qualquer forma, a inserção de mulheres nos conselhos de administração pode ser de muita valia particularmente por aportarem aos conselhos experiências não-tradicionais e de diferentes áreas. Nesse sentido, HILLMAN et al. (2002) e SINGH et al. (2008) mostram que, em comparação com seus pares, há uma maior probabilidade de mulheres possuírem diplomas superiores e TERJESEN et al., 2009) mostram que elas têm uma menor probabilidade de terem experiência em negócios. Por sua vez, essa perspectiva diferente pode ajudar os conselhos de administração a considerarem as implicações de decisões estratégicas em uma maior gama de partes interessadas, conforme se verá nos resultados apresentados nas próximas seções.

\subsection{Fatores que podem afetar a relação entre a Diversidade de Gênero nos Conselhos e a Responsabilidade Social Corporativa}

O impacto positivo a DGC proporcionam no desempenho de atividades de RSC pode variar conforme organizações e países. Isso quer dizer que, a depender do contexto (de países ou de companhias), o impacto da DGC na RSC pode ser mais ou menos positivo, conforme verificado por algumas pesquisas descritas a seguir.

No que se refere às organizações, mais especificamente às companhias, a distribuição interna de poder no conselho pode influenciar o impacto das mulheres quanto a um melhor desempenho social da companhia. Por um lado, FINKELSTEIN (1992) e FINKELSTEIN e MOONEY (2003) mostram que conselheiros poderosos podem controlar o processo decisório do órgão de tal forma que seja muito difícil que outras vozes, tais como as de conselheiras, sejam ouvidas. Por outro lado, se o poder relativo dos conselheiros é mais equilibrado, há maior

21 Mulheres e homens que não adequam seu comportamento aos estereótipos de gênero agem contrariamente às convenções sociais e, portanto, podem sofrer preconceito. Logo, os comportamentos geralmente associados aos homens, como a tomada de risco mais elevado e a assunção de desafios, são admirados nos homens, porém considerados negativos para as mulheres (GUTEK e MORASH, 1982; EAGLY e KARAU, 2002; HEILMAN e CHEN, 2005; AGARS, 2004; RYAN e HASLAM, 2005).

22 As pesquisas mostram que as conselheiras são mais interessadas em atividades filantrópicas e de serviço comunitário e possuem uma propensão maior de atuar junto à comunidade do que seus pares (HILLMAN et al., 2002; SINGH et al., 2008). 
probabilidade de todas as vozes do conselho contribuam de fato nas deliberações do processo decisório. Nesse sentido, BYRON E POST (2016) verificam que a relação entre a presença de mulheres nos conselhos e o desempenho social é maior em contextos nos quais a distribuição interna do conselho é mais equilibrada.

No que se refere às diferenças entre países, evidências empíricas tais como (DALTON e DALTON (2010), HARRIGAN (1981) e WRIGHT et al. (1995) mostram que a relação entre a participação de mulheres nos conselhos e a RSC é mais forte em países em que há maior igualdade de gênero. Assim, em contextos com maior igualdade de gênero, há maior probabilidade de que as mulheres nos conselhos possuam a experiência, o prestígio, a estrutura e o poder patrimonial que lhe garantem voz no conselho. Por outro lado, conforme mostram GLICK e FISKE (1999), os países com maior desigualdade de gênero (na educação, economia, saúde e política), os homens tendem a explorar seu status elevado exercendo, por exemplo, mais voz e poder no processo decisório. Assim, a situação de (des)igualdade de gênero prevalente no país se caracteriza por ser um tipo de instituição informal ${ }^{23}$ que modera o impacto da DGC no desempenho da RSC.

Por fim, existem evidências de que o impacto das mulheres nos conselhos quanto à RSC é maior em países com maior proteção aos acionistas, conforme mostram BYRON e POST (2016). Os conselhos de administração das companhias desses países podem ser mais motivados a aproveitar os recursos trazidos pelas conselheiras. Nesse sentido, companhias de países com maior proteção de acionistas provavelmente motivarão seus conselhos de administração a buscar informações e valores divergentes de seus membros de forma a considerar e integrar seus conhecimentos.

\section{Evidências Empíricas de Pesquisas Recentes}

Antes de apresentar as evidências sobre o impacto da diversidade de gênero nas atividades de RSC, é importante discutir como este complexo e multidimensional constructo que abrange uma variedade de questões sociais - costuma ser definido e mensurado.

De acordo com WOOD (1991), Responsabilidade Social Corporativa (RSC) referese à forma que uma companhia atende as expectativas de desempenho de seus principais stakeholders. Não existe até o momento um consenso na literatura sobre como a RSC deve ser medida. A maioria dos estudos tem operacionalizado este conceito em três categorias de medição distintas.

A primeira categoria é baseada em resultados observáveis resultantes de iniciativas de

23 Instituições informais, tais como estereótipos e ideologias, influenciam o comportamento e o processo cognitivo tanto dos atores sociais internos à uma companhia quanto aos externos (AGUILERA e JACKSON, 2003). 
RSC. Esta categoria, por sua vez, é subdividida em métricas gerais e específicas de RSC. As métricas gerais (ou multidimensionais) são baseadas em ratings preparados por terceiros visando capturar a ampla gama de impactos econômicos, sociais e ambientais causados pelas empresas. Classificações como os índices KLD, MSCI ESG, VIGEO e FTSE ESG, entre outras, são as fontes mais comuns dessas medidas de RSC direcionadas a múltiplos stakeholders. ${ }^{24}$ Por exemplo, o KLD é o índice holístico mais aceito e amplamente utilizado na pesquisa social corporativa desde sua criação em $1991 .{ }^{25} \mathrm{O}$ índice fornece classificações anuais de responsabilidade ambiental e social corporativa, e de governança para mais de 3.000 companhias de capital aberto. Ele é dividido em quatro dimensões principais: comunidade, produtos, funcionários e meio ambiente. Para cada dimensão, o KLD classifica as empresas em duas subdimensões com base nos seus "pontos fortes" ou "fortalezas" e "pontos de atenção" ou "preocupações". Por exemplo, é considerado um "ponto forte" ou "fortaleza" uma companhia apresentar um forte programa de prevenção da poluição ou usar materiais reciclados substancialmente. Por outro lado, produzir produtos químicos agrícolas (como pesticidas) ou ter suas receitas provenientes de combustíveis fósseis são considerados "pontos de atenção" ou "preocupações". Em geral, as subdimensões de fortalezas correlacionam-se mais fortemente com as "boas práticas", enquanto as subdimensões de preocupações estão associadas a práticas relacionadas a "causar ou permitir danos".

Por outro lado, as métricas específicas (ou unidimensionais) envolvem indicadores não-financeiros únicos, tais como: contribuições filantrópicas; iniciativas de sustentabilidade; práticas de negócios ambientalmente responsáveis (e.g. redução de emissões nocivas, uso de combustíveis alternativos, atividades de reciclagem); adoção e abrangência de códigos de ética; e existência de comitê de conselho dedicado à ética ou responsabilidade social.

A segunda categoria de mensuração da RSC é fundamentada em indicadores de reputação ética e social da companhia em relação aos seus stakeholders. A reputação da companhia engloba seu comportamento ético real e observado, bem como as percepções externas sobre sua conduta refletidas em notícias e em outros relatórios públicos. É geralmente mensurada em pesquisa social por meio da inclusão da companhia em rankings de empresas mais admiradas ou mais éticas (e.g. Fortune Corporate Reputation Index). Outra forma utilizada para medir a reputação utiliza o rastreamento das notícias, relatórios e reivindicações das partes interessadas relacionadas com a conduta das empresas. Um exemplo é o Índice de Reputação EthicalQuote desenvolvido pela Covalence, que congrega informações acerca de 50 critérios relacionados a RSC e ambiental, incluindo: desempenho ambiental; condições de trabalho dignas; direitos humanos; responsabilidade do produto, entre outros. ${ }^{26}$ Ao analisar comportamentos éticos

24 O site http://www.csrhub.com/ resume a maioria dos ratings ambientais, sociais e de governança.

25 Para mais informações sobre o índice KLD, suas qualidades e limitações, ver Chatterji et al. (2009).

26 Para mais informações sobre o Covalence EthicalQuote, vide http://www.ethicalquote.com/. 
materializados na quantidade de notícias positivas e negativas, este índice de reputação ética é construído de forma a refletir o comportamento observado da empresa.

A terceira categoria de mensuração de RSC tem por base indicadores de integridade, precisão e transparência de relatórios. Estes estudos costumam analisar se as companhias: i) cumprem as leis e regulamentos (e.g. apresentando menor incidência de fraudes corporativas e de mercado de capitais); ii) fornecem melhores relatórios financeiros (e.g. oferecendo demonstrações financeiras mais precisas e qualidade superior das receitas); e, iii) respondem às demandas dos stakeholders, divulgando voluntariamente seus impactos sociais e ambientais. A Tabela 1, no fim do artigo, resume as três categorias de mensuração de RSC descritas nesta seção, incluindo suas subcategorias e indicadores utilizados pela literatura. ${ }^{27}$

\section{Impacto Positivo da Diversidade de Gênero nos Conselhos de Administração em Iniciativas de Responsabilidade Social Corporativa}

\subsection{Medidas Gerais de Responsabilidade Social Corporativa}

Um dos primeiros estudos sobre o impacto da diversidade de gênero em classificações de RSE é de 2004. WEBB (2004) dividiu as companhias em dois grupos usando o Índice KLD: uma amostra com companhias "socialmente responsáveis" contendo 394 companhias e outra correspondente de companhias "não socialmente responsáveis" (do mesmo setor e porte aproximado). A autora observou que as companhias socialmente responsáveis tinham uma porcentagem significativamente maior de mulheres no conselho de administração $(13 \%)$ do que os conselhos de companhias não socialmente responsáveis (8\%).

Outro estudo que chama a atenção é o de BEAR et al. (2010). Neste artigo, foram analisadas duas questões: o impacto da DGC em atividades de RSC e a relação entre RSC e reputação corporativa. Para tanto, os autores utilizaram uma amostra com 51 companhias da área da saúde. Os autores concluíram que o número de mulheres no conselho é significativamente associado com as classificações de "fortalezas" ou "pontos fortes” do Índice KLD. Mais do que isso, a RSC da companhia se eleva na medida que aumenta o número de conselheiras. Segundo os autores, os resultados sugerem que as contribuições das mulheres ao conselho na área da RSC têm maior probabilidade de serem consideradas quando deixarem de ser mero simbolismo ("tokenismo"). ${ }^{28}$ Em suma, a DGC parece desempenhar um papel importante no aumento da reputação corporativa, contribuindo para a RSC da empresa.

\footnotetext{
27 Ela apresenta, ainda, a lista de artigos (detalhados nas subseções seguintes) que fornecem apoio empírico para o argumento de que a diversidade de gênero conduz a melhores resultados de RSC.

28 O conceito de simbolismo (ou o conhecido termo "tokenism") visa traduzir uma prática de fazer um esforço superficial ou simbólico de forma a recrutar um pequeno número de pessoas provenientes de grupos subrepresentados para dar a aparência de igualdade sexual, racial (entre outras) dentro de uma força de trabalho ou grupo, transformando essas pessoas em troféus, símbolos de uma diversidade que, na verdade, não existe.
} 
Do mesmo ano, o artigo de NIELSEN e HUSE (2010) construiu um índice de "controle estratégico do conselho". Esse índice mensura o envolvimento do conselho de administração em decisões relativas a: (1) responsabilidade social corporativa; (2) recursos humanos; (3) qualidade do produto; e (4) saúde, meio ambiente e segurança. Os autores analisaram 201 companhias norueguesas e descobriram que a proporção de conselheiras está positivamente associada ao controle estratégico do conselho. Eles também concluíram que os efeitos positivos das conselheiras quanto à eficácia do conselho são resultado - ao menos parcialmente - de uma melhora nas atividades de desenvolvimento do conselho ${ }^{29}$ e também de uma redução do nível de conflito interno do órgão. Para os autores, esses resultados estão relacionados a diferentes estilos de liderança e perspectiva mais abrangente das mulheres acerca das diferentes partes interessadas. ${ }^{30}$

Outro artigo, MALLIN e MICHELON (2011), investigou a relação entre a reputação do conselho e o desempenho social corporativo. As autoras analisaram uma amostra de 176 companhias da lista "Best Corporate Citizens" de 2005 a 2007, na qual a DGC foi um dos atributos utilizados para medir a reputação do conselho. $\mathrm{O}$ trabalho mostrou que a proporção de conselheiras está associada positivamente ao desempenho social das companhias medido pelo Índice KLD quanto às classificações sociais e ambientais. Esses resultados são ainda mais fortes para os indicadores específicos relacionados à comunidade, aos funcionários e aos direitos humanos.

Com base em outra amostra, ZHANG (2012) analisou 475 companhias listadas em bolsa de valores elencadas na lista Fortune 500 entre os anos de 2007 e 2008. Seus resultados apontam que DGC está positivamente relacionada ao desempenho social das companhias medido pelo Índice KLD. A autora foi além e distinguiu os aspectos institucionais e técnicos subjacentes ao índice KLD. O aspecto institucional reflete a resposta da companhia às pressões institucionais e envolve ações voltadas à comunidade e meio ambiente, enquanto o aspecto técnico trata do relacionamento da companhia com as partes interessadas essenciais para as operações comerciais (funcionários, consumidores e acionistas). O resultado mostra que uma maior proporção de mulheres em conselhos de administração está associada a melhores classificações de KLD em ambos os aspectos institucional e técnico. Dessa forma, ter mais mulheres nos conselhos melhora a proteção de diferentes partes interessadas.

No que se refere à diversidade em geral, os autores HAFSI e TURGUT (2013) construíram duas medidas de diversidade de conselhos: a "diversidade demográfica" e a "diversidade estrutural". Enquanto a primeira mede a diversidade dos membros dentro de um determinado conselho (tendo por base gênero, idade, etnia, experiência e propriedade acionária), a segunda

29 As atividades de desenvolvimento do conselho envolvem avaliação do conselho, programas de desenvolvimento do conselho, introdução de novos membros e etc.

30 Ver NIELSEN e HUSE (2010, p. 136 e 143). 
mede a diversidade entre conselhos de diferentes companhias (tendo por base o tamanho do conselho, a independência dos membros, dualidade de liderança e a participação acionária dos conselheiros). Com base nessas medidas, os autores analisaram 95 companhias da lista S\&P 500 e verificaram que (i) a diversidade demográfica dos conselhos é fator determinante do desempenho social das companhias, e (ii) essa relação é moderada pela diversidade estrutural dos conselhos. Os resultados indicaram claramente que a inclusão de conselheiras resulta em um melhor desempenho social para a empresa. ${ }^{31}$

De forma a testar uma hipótese diferente, BOULOUTA (2013) investigou o impacto da DGC em atividades de RSC relacionando-o à literatura feminista e às teorias do papel social e estereótipos que mostram que a "ética do cuidado" e a empatia tendem a provocar uma resposta mais forte em mulheres, evitando causar prejuízos a terceiros. ${ }^{32}$ Além disso, a autora utilizou as classificações do KLD que são divididas em "pontos fortes" e em práticas "prejudiciais", conforme mencionado na seção anterior. Consolidando esses temas, a hipótese da autora é de que uma maior DGC influenciaria as métricas de RSC de forma a evitar práticas prejudiciais a terceiros. O artigo investigou 126 companhias da lista S\&P 500 durante cinco anos e o resultado comprovou a hipótese. Especificamente, uma maior DGC exerce forte influência sobre as métricas de RSC no que tange às práticas prejudiciais. Dessa forma, conselhos com maior DGC tendem a ser mais relevantes na prevenção de danos a terceiros.

Outras duas pesquisas recentes merecem destaque por tratarem do impacto da DGC em medidas multidimensionais de RSC. Na primeira, SUNDARASEN et al. (2016) entrevistaram 450 companhias listadas na "Bursa Malaysia" durante dois anos (2011-2012). Os autores descobriram que a presença de mulheres nos conselhos é a única variável - dentre um índice composto por 28 itens - que afeta positivamente o nível de iniciativas de RSC das empresas. ${ }^{33}$

A segunda pesquisa utilizou um método chamado de meta-análise. ${ }^{34}$ BYRON e POST (2016) investigaram os resultados agregados de dezenas de estudos que relacionaram a DGC à RSC, e combinaram os resultados de 84 estudos contendo uma amostra de 26.710 companhias de mais de 20 países. As autoras encontraram dois resultados principais. O primeiro foi de que a relação entre DGC e o desempenho social corporativo é geralmente positiva. Especificamente, a média do efeito que relaciona a DGC ao desempenho social é aproximadamente cinco vezes maior do que a média que associa a DGC ao desempenho financeiro. Esse resultado se deve ao

31 De acordo com HAFSI e TURGUT (2013, p. 474): “( ...) in social matters most firms are beginners and boards are unclear about what behavior is best. Women in such a case can be seen as providing the sensitivity and guidance that makes the difference in CSP [Corporate Social Performance]. This is a clear vindication of the idea that gender diversity breeds better sensitivity to social issues".

32 Conforme apresentado na seção 1 deste artigo. Ver Gilligan (1982), Eagly (2009) e Slote (2007).

33 Conforme SUNDARASEN et al. (2016, p. 35), "board composition in an emerging market is relatively ineffective in improving CSR [Corporate Social Responsibility] initiatives, with the exception of women on board".

34 O método da meta-análise é uma pesquisa quantitativa agregando resultados de pesquisas quantitativas anteriores de forma a buscar encontrar uma verdade comum e subjacente por meio de uma média estatística dos resultados dos estudos individuais. 
conselho de administração ter mais controle em relação as atividades de RSC - que se relacionam ao desempenho social - do que ao desempenho financeiro. O segundo é ainda mais interessante. Mostra que a relação entre DGC e desempenho social corporativo é ainda mais positiva em contextos nacionais que apresentam maior proteção dos acionistas e maior equidade de gênero, conforme apresentado na seção 1.3. Assim, a DGC pode ter diferentes impactos a depender do contexto, que pode permitir ou não a influência das conselheiras no processo decisório.

\subsection{Medidas Específicas de Responsabilidade Social Corporativa}

Um dos primeiros estudos que investigou o impacto da DGC em relação à medidas unidimensionais de RSC é o de WILLIAMS (2003). Ele analisou a potencial influência de conselheiras sobre atividades filantrópicas das empresas utilizando uma amostra de 185 companhias dos EUA de 1991 a 1994. Seus resultados mostram que as companhias com maior DGC se engajam mais em atividades filantrópicas do que outras companhias. Os resultados são ainda mais fortes para atividades relacionadas ao serviço comunitário e às artes.

Vale destacar a pesquisa de POST et al. (2011) que investigou o impacto da composição do conselho na responsabilidade ambiental. Para tanto, utiliza dados de 78 companhias químicas e de eletrônicos da lista Fortune 1000 do ano de 2007. O resultado principal do estudo foi descobrir que as companhias cujos conselhos eram compostos por três ou mais mulheres recebiam classificações melhores quanto à responsabilidade ambiental. Esses resultados corroboram a teoria da massa crítica para a qual mulheres e minorias raciais ou étnicas terão impacto nas decisões do conselho quando passarem de "troféus", ou simbolismo, para uma minoria relevante do órgão.

Outro artigo sobre responsabilidade ambiental é o de WALLS et al. (2012) que investigou a relação entre governança corporativa e desempenho ambiental. A pesquisa é extensa, pois utilizou dados de 313 companhias da lista S\&P 500 pertencentes a 29 setores ao longo de oito anos, totalizando 2.002 observações. Duas conclusões se destacam. A primeira mostra que o desempenho ambiental foi pior em companhias com menos mulheres nos conselhos. A segunda verifica que, nas companhias com maior DGC, havia menos fatores de preocupação ambiental, especialmente quando de propriedade concentrada e participação de investidores institucionais.

Vale destacar, ainda, quatro artigos recentes que fornecem mais evidências sobre o impacto da DGC em indicadores específicos de RSC. O artigo de GARCIA-SANCHEZ et al. (2015) investigou a relação entre o conselho e os códigos de ética em 12 países. Após analisar 760 companhias listadas durante seis anos (totalizando 5.380 observações), o artigo mostra que as companhias com maior DGC implementam os códigos de ética mais desenvolvidos. Quanto maior o número de mulheres e de membros independentes no conselho, maior o nível de escopo do código de ética implementado. Para os autores, os resultados indicam que as conselheiras 
e os independentes são mais sensíveis a demandas éticas, além de mais preocupados com a conformidade e a satisfação de partes interessadas.

A segunda pesquisa de 2015 também aborda questões éticas. ISIDRO e SOBRAL (2015) realizaram estudo transversal sobre os impactos diretos e indiretos da DGC sobre o valor da empresa, a ética e a conformidade, investigando 922 companhias de 16 países europeus de 2010 a 2012. As autoras concluíram que a presença de mulheres no conselho está positivamente relacionada ao desempenho financeiro (com base no retorno sobre ativos e retorno sobre vendas) e à conformidade ética e social que, por sua vez, está positivamente relacionada ao valor da empresa. Os resultados sugerem existir um efeito indireto da DGC sobre o valor da empresa resultante de um maior nível de conformidade, algo que não é capturado pelas análises de desempenho financeiro. ${ }^{35}$

A terceira pesquisa, de GLASS et al. (2015), investiga o efeito da presença de mulheres na alta administração das empresas sobre a sustentabilidade ambiental, utilizando uma extensa base de dados contendo todas companhias da lista Fortune 500 durante o período de dez anos (de 2001 a 2010). O artigo apresenta quatro resultados principais: (i) empresas com mais mulheres na alta administração são mais eficazes na persecução de estratégias favoráveis ao meio ambiente; (ii) a DGC está relacionada a um efeito positivo pequeno na probabilidade da companhia apoiar iniciativas ambientais favoráveis; (iii) companhias cujas conselheiras atuam em mais de um conselho apresentam práticas ambientais mais fortes; (iv) companhias com maior DGC cujos presidentes são homens têm maior probabilidade de ter um histórico ambiental sólido.

Ainda em relação ao meio ambiente, POST et al. (2015) investigaram como a DGC impacta o desempenho ambiental das empresas por meio da formação de alianças sustentáveis, tais como alianças de energia renovável. O artigo utilizou a população das 36 companhias que compõem o setor de petróleo e gás dos EUA durante cinco anos. O resultado principal mostrou que, quanto maior a DGC, maior a probabilidade de a companhia formar alianças de sustentabilidade que, por sua vez, contribuem positivamente para o desempenho ambiental das companhias.

\section{Impacto Positivo da Diversidade de Gênero nos Conselhos de Administração em Relação à Reputação Ética e Social}

A influência da DGC também é investigada em sua relação com a reputação ética e social das companhias. Um dos primeiros estudos neste tema é o BERNARDI et al. (2006) que analisou o impacto da DGC na reputação ética. Investigando todas as companhias da lista Fortune

35 Os autores também observam que não há diferença estatística entre a proporção de conselheiras em países com leis de quotas sem sanções, e países que possuem apenas iniciativas voluntárias. Segundo os autores, esse resultado sugere que a lei de quotas sem sanção não tem efeito no aumento da diversidade de gênero nos conselhos de administração. 
500, os autores observaram que uma maior DGC está positivamente associada à companhia compor a lista das mais éticas, "Ethisphere Magazine's World's Most Ethical Companies". As companhias dessa lista apresentavam uma representação média significativamente maior de conselheiras $(18,5 \%$ contra $14,1 \%)$.

Outro estudo acerca do tema é BRAMMER et al. (2009) que analisou os dados acerca da reputação de 199 companhias britânicas usando a pesquisa "Britain's admired companies" da "Management Today", publicação que emprega metodologia semelhante à da conhecida lista das mais admiradas da Revista Fortune ("World's Most Admired Companies"). Sua principal conclusão é a de que existe um efeito reputacional associado à DGC, mas que depende do setor de atuação da companhia, especificamente naqueles próximos ao consumidor final.

A pesquisa de ZHANG et al. (2013) analisou o impacto da DGC em medidas de RSC relacionadas à reputação utilizando a lista das mais admiradas da Fortune, "World's Most Admired Companies". Com dados das 516 maiores companhias listadas dos EUA, abrangendo 64 setores diferentes, os autores descobriram uma forte relação entre uma maior DGC e uma melhor reputação de RSC (dentro do mesmo setor). O estudo também revelou que as mulheres, entre todos os tipos de conselheiros, tiveram o maior efeito sobre a reputação de RSC. Para os autores, estruturar um conselho com base nesses resultados pode ser abordagem eficaz para melhorar a legitimidade moral de uma empresa.

Também foi conduzida uma análise cross-country sobre reputação corporativa. BASELGA-PASCUAL et al. (2014) realizaram uma extensa análise empírica, de 2005 a 2010, utilizando uma amostra de 43 grandes instituições financeiras listadas de 13 países: Austrália, Alemanha, Bermudas, Brasil, Canadá, Espanha, Estados Unidos, França, Itália, Japão, Reino Unido, Suíça e Taiwan. Após conduzirem diferentes análises, os autores encontraram fortes evidências de que a reputação ética das instituições financeiras está positivamente associada à DGC. Esses resultados corroboram com o argumento de que uma supervisão mais rigorosa do conselho melhora a reputação ética das instituições financeiras.

Por fim, a pesquisa de PERSONS (2015) congregou dez características de governança corporativa das 50 companhias mais admiradas do mundo (World's Most Admired Companies da Revista Fortune) e comparou com as características de seus pares não admirados. Sua principal conclusão mostra que as companhias admiradas têm um percentual maior de conselheiras, entre outros atributos de governança corporativa.

\section{Impacto Positivo da Diversidade de Gênero no Conselho quanto à Integridade das Companhias e Transparência de Relatórios}

\subsection{Conformidade às Leis e Normas}


Destacam-se três estudos recentes na linha de pesquisa sobre a relação da DGC e a conformidade das empresas às leis e normas. O primeiro deles tem como enfoque a DGC em relação a fraudes no mercado de capitais. CUMMING et al. (2012) foi o primeiro a analisar empiricamente o impacto da DGC em um amplo espectro de fraudes no mercado de valores mobiliários. $\mathrm{O}$ artigo analisou 1422 casos de fraude cometidos em 742 companhias durante o período de dez anos (de 2001 a 2010). Os casos analisados envolvem ações ilegais de recompra de ações, reporte de lucros inflacionados, invenção de ativos, desfalque de acionistas, manipulação de preço de ações e etc. Os autores encontraram fortes evidências de que a importância da DGC quanto à mitigação de fraudes de mercado reside no próprio mecanismo da diversidade. Especificamente, os autores observaram que, a partir da percentagem média de conselheiras $(13,2 \%)$, um aumento de um desvio padrão na proporção de conselheiras $(9,1 \%)$ está associado a uma redução de 14,6\% na probabilidade de fraude. A presença de conselheiras também é mais eficaz para mitigar tanto a presença de fraudes quanto a sua gravidade. Segundo esse estudo, a porcentagem ideal de mulheres nos conselhos de administração a fim de minimizar fraudes de valores mobiliários é de $50 \%{ }^{36}$

Outro estudo muito importante com esta temática foi publicado em 2013. STEFFENSMEIER et al. (2013) investigaram 83 crimes corporativos graves dos EUA de 2002 a 2009, incluindo manipulação contábil, esquemas Ponzi, insider trading e etc. O artigo concluiu que as mulheres estavam ausentes dos principais grupos criminosos em todos os casos. Quando havia sua participação, elas exerciam papéis muito menores e recebiam um lucro substancialmente menor - quando recebiam algum lucro. ${ }^{37}$ Os autores verificaram que os grupos compostos $100 \%$ por homens representavam quase $3 / 4$ de todos os crimes corporativos e nenhum caso envolveu um grupo composto $100 \%$ por mulheres. A pesquisa revelou, ainda, que todas as fraudes executadas individualmente foram perpetradas por homens ${ }^{38}$ e a grande maioria dos criminosos corporativos eram do sexo masculino (91\%). Esses 9\% de mulheres está bem abaixo da ocupação da alta gestão (15\%) e de gerência média (50\%) nos EUA.

Por fim, o artigo de SCARLAT et al. (2015) foi o primeiro a documentar que a cultura ética da empresa - medida pela lucratividade de informações privilegiadas utilizadas pelos funcionários - depende do gênero dos principais executivos da companhia. Os autores investigaram companhias norte-americanas que passaram por transição de seus executivos

\footnotetext{
36 CUMMING et al. (2012) asseveram o seguinte: “we find evidence that board of directors' gender diversity facilitates improved corporate governance, insofar as that the likelihood and severity of securities fraud is mitigated, implying that regulators and policymakers should consider the worldwide call for more gender-diverse boards".

37 Em um forte contraste com os homens, os autores encontraram que mais da metade das mulheres envolvidas nos crimes não ganhou lucro algum $(56 \%)$ ou se beneficiaram muito pouco $(8 \%)$. A disparidade entre o lucro de homens e mulheres se manteve também nos poucos casos em que mulheres ocupavam posições de destaque nos crimes.
}

38 Apenas três mulheres (8\%) foram líderes dos grupos, sendo que duas delas exerceram a liderança em conjunto com seus maridos. 
principais (presidentes e diretores financeiros) de 2003 a 2011. Foram analisados os dados de 86 companhias cujos cargos eram ocupados por homens e passaram a ser ocupados por mulheres e 1.276 companhias nas quais essa transição ocorreu apenas entre homens. A principal conclusão é a de que há uma diminuição significativa na lucratividade do insider trading quando o cargo deixa de ser ocupado por um homem e passa para uma mulher (em comparação com transições entre homens). Para reforçar seus resultados, os autores também investigaram o contrário, o que ocorre com a lucratividade do insider trading quando o cargo deixa de ser ocupado por uma mulher e volta a ser ocupado por um homem..$^{39}$ Nestes casos, houve uma reversão impressionante: os lucros provenientes de insider trading voltaram a ser significativamente mais altos após a volta de um homem para os cargos. Para os autores, esses resultados evidenciam que as executivas mudam a cultura corporativa da organização por meio de um tom mais ético.

\subsection{Impactos Positivos da Diversidade de Gênero no Conselho na Qualidade dos Relatórios Financeiros}

O primeiro estudo que relaciona a diversidade de gênero na alta gestão e a qualidade das informações financeiras foi publicado em 2008 por KRISHNAN e PARSONS (2008). Controlando por porte e setor das companhias, os autores examinaram diversas medidas de "qualidade dos lucros" ${ }^{40}$ de 353 companhias da lista Fortune 500, de 1996 a 2000. Os autores dividiram as companhias com base na diversidade de gênero da alta gestão: alta diversidade (companhias com 14,3\% a 38,3\% de mulheres) e baixa diversidade (companhias com 0\% a $5,1 \%$ de mulheres). Então, verificaram se a prevalência de mulheres na alta gestão predizia a qualidade dos lucros reportados. O principal resultado mostrou que companhias com mais mulheres na alta gestão são mais rentáveis e têm maior retorno das ações após as ofertas públicas iniciais. Esse resultado positivo não foi criado pela "administração de lucros" "qualidade dos lucros" é positivamente associada à diversidade de gênero na alta administração. A pesquisa de LABELLE et al. (2010) também chega a resultados semelhantes, que corroboram com a ideia de que a diversidade de gênero tem efeitos na cultura organizacional tornando-a avessa a práticas negativas, tais como a "administração de lucros". ${ }^{42}$

O estudo de GUL et al. (2011) investigou se a DGC em companhias listadas nos EUA as torna mais transparentes e incentiva a incorporação de informações sobre o preço da ação. Após a análise de 5.021 observações durante sete anos (de 2001 a 2007), os autores descobriram que

39 Durante o período analisado, das 86 companhias da amostra que tiveram seus cargos de presidência ou diretoria financeira ocupados primeiro por homens e depois por mulheres, 24 delas trocaram novamente de executivos e voltaram a ter homens na presidência e diretoria financeira.

40 A qualidade dos lucros é o grau em que os lucros relatados capturam a realidade econômica da empresa, considerada boa prática.

41 A administração dos lucros, considerada má prática, envolve a seleção de estimativas contábeis que resultam em relatórios financeiros vantajosos para a empresa (ou seus gestores) à custa de partes interessadas externas.

42 Segundo LABELLE et al. (2010, p. 348): “(...) firms should go beyond affirmative action not only by increasing diversity in the boardrooms and among employees, but also by developing corporate diversity management policies as part of the organizational culture". 
os preços das ações de companhias com maior DGC refletem mais informações. Ainda, a maior DGC melhora o "nível de informação" pública das grandes companhias e ii) maior estímulo à coleta de informações das pequenas empresas. $\mathrm{O}$ aumento da divulgação pública acaba protegendo investidores desinformados e aumentando a confiança destes no mercado. Para os autores, uma maior DGC melhora a qualidade da informação por meio de um melhor monitoramento, atuando como mecanismo de governança corporativa.

Também de 2011 é a pesquisa de SRINIDHI et al. (2011) que investigou a relação entre DGC e a qualidade dos lucros. Os autores analisaram 2.480 observações de companhias listadas nos EUA ao longo de sete anos (de 2001 a 2007) e concluíram que aquelas com maior DGC exibiam melhor qualidade dos lucros em virtude da melhora de supervisão do conselho. Além disso, os autores observaram que companhias com maior DGC, especialmente com a presença de mulheres no comitê de auditoria, apresentaram melhores práticas de prestação de informações financeiras, tendo o potencial de aumentar a confiança do investidor nos relatórios financeiros.

Utilizando uma abordagem diferente acerca dos relatórios financeiros, ABBOTT et al. (2012) investigaram a relação entre a DGC e a qualidade dos relatórios financeiros analisando se DGC reduz a reapresentação de relatórios utilizando uma amostra de 278 companhias listadas nos EUA ao longo de cinco anos. Após diversos testes, a conclusão é que há uma forte associação entre a presença de ao menos uma mulher no conselho e uma menor probabilidade de reapresentação de relatórios. Para os autores, os resultados empíricos são consistentes com o argumento de que ao menos uma mulher no conselho contribui para o órgão manter a independência mental, diminui o pensamento de grupo ("groupthink") e aumenta a capacidade do conselho monitorar os relatórios financeiros.

Por fim, o estudo de HO et al. (2015) investigou se há relação entre o gênero de quem ocupa a presidência da empresa, sua liderança ética e conservadorismo contábil usando um amplo conjunto de dados de 13.206 observações nos EUA de 1996 a 2008. Sua principal conclusão foi a de que as companhias com presidentas reportaram seus lucros de forma mais conservadora. Esta associação é mais forte em companhias expostas a altos riscos contenciosos e de aquisição. Segundo os autores, os resultados destacam os benefícios da diversidade de gênero para a integridade dos relatórios financeiros, evitando distorções fraudulentas.

\subsection{Impactos Positivos da Diversidade de Gênero no Conselho na Qualidade dos Relatórios Não-Financeiros}

Além do impacto positivo na qualidade de relatórios financeiros, uma linha de pesquisa

43 O conceito de "nível de informação" ou "informatividade" ("informativeness") relaciona-se com os atuais retornos das ações e as mudanças nos lucros futuros. Quanto mais conteúdo existe nas informações sobre ganhos futuros, mais informação é possível sobre as mudanças nos lucros futuros. 
recente passou a investigar o impacto da maior DGC na qualidade de relatórios não-financeiros, principalmente nos de sustentabilidade.

Uma das pesquisas pioneiras é a de CIOCIRLAN e PETTERSSON (2012) que analisaram 94 companhias dos EUA no ano de 2008. As autoras concluíram que as companhias com maior DGC tendem a apresentar uma maior preocupação com as mudanças climáticas.

Também de 2012, o estudo de FODIO e OBA (2012) é um dos poucos com dados de mercados emergentes. Os autores investigaram iniciativas de RSC relacionadas ao meio ambiente, à filantropia estratégica e ao desenvolvimento comunitário de 16 grandes companhias da Nigéria, de 2005 a 2007. A principal conclusão foi que a presença de mulheres e a sua proporção no conselho exercem um impacto positivo significativo na divulgação de informação ambientais da empresa. Com resultados similares, RAO et al. (2012) verificaram a existência de uma relação positiva significativa entre a DGC e a extensão da informação ambiental, analisando amostra de 100 companhias listadas australianas.

Indo além de relatórios ambientais, FRIAS-ACEITUNO et al. (2013) realizaram uma extensa análise acerca da qualidade de informações não financeiras de 568 companhias de 15 países, de 2008 a 2010. Os autores concluíram que a DGC é um dos fatores mais importantes para a transparência das informações econômicas, sociais e ambientais consolidadas em um relatório integrado. Este efeito é observado em companhias com diversos modelos de governança, tais como anglo-saxão, germânico e latino.

Do mesmo ano, SETÓ-PAMIES (2013) analisou uma pesquisa cross-country com empresas de 22 países para verificar a relação entre conselheiras e RSC. Utilizando dados de 94 grandes companhias da lista Global 100 Most Sustainable Corporations de 2011, a autora verificou que as companhias com maior DGC são socialmente mais responsáveis em relação a uma ampla gama de práticas de sustentabilidade. Sua descoberta sugere que maior DGC tem um papel relevante na condução de práticas de RSC.

Também quanto a relação entre DGC e sustentabilidade, FERNANDEZ-FEIJOO et al. (2014) analisaram cerca de 2.400 observações de 22 países e chegaram a duas constatações principais. Em primeiro lugar, os níveis de transparência de RSC são mais elevados em países cuja presença de mulheres nos conselhos contava com, ao menos, três mulheres. Em segundo lugar, os países com maior igualdade de gênero têm mais companhias cujos conselhos são compostos por, ao menos, três mulheres. Seus resultados amparam o argumento de que o nível dos relatórios de RSC tende a ser melhor em países cujos conselhos são compostos por, pelo menos, três mulheres.

Por fim, dois trabalhos recentes fornecem mais evidências sobre o impacto positivo da DGC em relação à divulgação voluntária acerca de questões ambientais. O primeiro estudo, 
de LIAO et al. (2014), analisou os dados de 329 companhias listadas do Reino Unido e sua principal conclusão é que há uma forte associação positiva entre a DGC e a propensão de companhias divulgarem voluntariamente informações sobre emissão de gás de efeito estufa (“GHG”). O segundo estudo, de BEN-AMAR et al. (2015), analisou 541 observações de companhias listadas canadenses de 2004 a 2008. Os autores descobriram que a probabilidade de divulgação voluntária de mudanças climáticas (acerca da emissão de GHG) aumenta junto com o aumento da porcentagem de mulheres nos conselhos. Os resultados também apoiam a teoria da massa crítica, pois descobriram a necessidade de ao menos duas conselheiras para verificarem a influência positiva nas divulgações de mudança climática.

\section{Conclusões}

Este trabalho buscou revisar e consolidar os principais resultados da literatura que investiga o impacto da maior diversidade de gênero nos conselhos sobre as iniciativas de responsabilidade social corporativa. A análise agregada de dezenas de trabalhos empíricos mostra que a maior diversidade de gênero nos conselhos está relacionada a diversos impactos positivos, tais como: melhores indicadores de responsabilidade social corporativa, melhor reputação ética e social, maior conformidade às leis e normas, e melhor qualidade dos relatórios divulgados pelas empresas.

A ONU, por meio de diversas iniciativas, tais como o Pacto Global e os Princípios de Empoderamento Feminino, estimula o maior empoderamento feminino em cargos de liderança das companhias. Nesse sentido, buscou-se oferecer subsídios para corroborar o argumento de que a diversidade de gênero nos conselhos atua como uma via de mão dupla em relação a outras importantes prioridades de direitos humanos, tais como respeito aos funcionários, meio ambiente e partes interessadas em geral.

Em suma, companhias com mais mulheres nos conselhos apresentam melhores práticas de responsabilidade social e ambiental corporativa, têm menor incidência de fraudes corporativas e do mercado de capitais, respeitam mais as partes interessadas e o meio ambiente, e prestam contas de forma voluntária.

Como conclusão geral, constata-se que a diversidade de gênero na alta gestão deve ser vista como prioridade por dois motivos principais. De um lado, por contribuir diretamente com os Princípios de Empoderamento das Mulheres da ONU. Do outro, por contribuir indiretamente para a promoção dos Princípios do Pacto Global, particularmente para aqueles relacionados ao meio ambiente e ao combate à corrupção. 
Tabela 1. Medidas de Responsabilidade Social Corporativa (RSC) e Evidências Empíricas do Impacto Positivo da Diversidade de Gênero nos Conselhos de Administração (DGC).

\begin{tabular}{|c|c|c|c|c|}
\hline Constructo & $\begin{array}{l}\text { Categoria } \\
\text { de Medida }\end{array}$ & $\begin{array}{l}\text { Subcategoria } \\
\text { de medida }\end{array}$ & Indicadores & $\begin{array}{c}\text { Evidências Empíricas da } \\
\text { Diversidade de Gênero } \\
\text { nos Conselhos }\end{array}$ \\
\hline \multirow{6}{*}{$\begin{array}{l}\text { Responsabilidade } \\
\text { Social } \\
\text { Corporativa } \\
\text { (RSC) }\end{array}$} & \multirow{2}{*}{$\begin{array}{c}\text { Iniciativas de } \\
\text { RSC }\end{array}$} & $\begin{array}{l}\text { Medidas } \\
\text { Gerais } \\
\text { de RSC }\end{array}$ & $\begin{array}{l}\text { Rankings multidimensionais } \\
\text { elaborados por terceiros, tais } \\
\text { como KLD, MSCI ESG, } \\
\text { VIGEO e FTSE ESG }\end{array}$ & $\begin{array}{c}\text { Webb (2004) } \\
\text { Bear et Al. (2010) } \\
\text { Nielsen e Huse (2010) } \\
\text { Mallin e Michelon (2011) } \\
\text { Zhang et al. (2012) } \\
\text { Boulouta et al. (2013) } \\
\text { Hafsi e Turgut (2013) } \\
\text { Byron e Post (2016) } \\
\text { Sundarasen et al. (2016) }\end{array}$ \\
\hline & & $\begin{array}{l}\text { Medidas } \\
\text { Específicas } \\
\text { de RSC }\end{array}$ & $\begin{array}{l}\text { - Filantropia e Doações } \\
\text { - Iniciativas de Sustentabilidade } \\
\text { - Desempenho Ambiental } \\
\text { Corporativo } \\
\text { - Existência e Abrangência do } \\
\text { Código de Ética } \\
\text { - Outros impactos específicos } \\
\text { em partes interessadas }\end{array}$ & $\begin{array}{c}\text { Williams (2003) } \\
\text { Post et al. (2011) } \\
\text { Walls et al. (2012) } \\
\text { Garcia-Sanchez et al. (2015) } \\
\text { Glass et al. (2015) } \\
\text { Isidro e Sobral (2015) } \\
\text { Post et al. (2015) }\end{array}$ \\
\hline & $\begin{array}{l}\text { Reputação } \\
\text { Ética e Social }\end{array}$ & $\begin{array}{c}\text { Medidas de } \\
\text { Reputação Ética } \\
\text { e Social }\end{array}$ & $\begin{array}{l}\text { - Lista das Companhias Mais } \\
\text { Eticas } \\
\text { - Lista das Companhias Mais } \\
\text { Admiradas } \\
\text { - Rankings de Reputação } \\
\text { Corporativa }\end{array}$ & $\begin{array}{c}\text { Bernardi et al. (2009) } \\
\text { Brammer et al. (2009) } \\
\text { Bear et al. (2010) } \\
\text { Zhang et al. (2013) } \\
\text { Baselga-Pascual et al. (2014) } \\
\text { Persons (2015) }\end{array}$ \\
\hline & \multirow{3}{*}{$\begin{array}{l}\text { Integridade da } \\
\text { Companhia e } \\
\text { Transparência } \\
\text { dos Relatórios }\end{array}$} & $\begin{array}{l}\text { Conformidade } \\
\text { às leis e } \\
\text { normas }\end{array}$ & $\begin{array}{l}\text { - Menor Incidência de Fraudes } \\
\text { Corporativas } \\
\text { - Menor Incidência de Fraudes } \\
\text { no Mercado de Capitais }\end{array}$ & $\begin{array}{l}\text { Cumming et al. (2012) } \\
\text { Steffensmeier et al. (2013) } \\
\text { Scarlat et al. (2015) }\end{array}$ \\
\hline & & $\begin{array}{l}\text { Relatórios } \\
\text { Financeiros }\end{array}$ & $\begin{array}{l}\text { - Conservadorismo Contábil } \\
\text { - Qualidade dos Lucros } \\
\text { - Acurácia dos Relatórios } \\
\text { Financeiros }\end{array}$ & $\begin{array}{l}\text { Krishnan e Parsons (2008) } \\
\text { Labelle et al. (2010) } \\
\text { Gul et al. (2011) } \\
\text { Srinidhi et al. (2011) } \\
\text { Abbott et al. (2012) } \\
\text { Ho et al. (2015) }\end{array}$ \\
\hline & & $\begin{array}{l}\text { Relatórios } \\
\text { Não } \\
\text { Financeiros }\end{array}$ & $\begin{array}{l}\text { - Divulgação Voluntária de } \\
\text { Questões Ambientais } \\
\text { - Atenção a Demandas de Partes } \\
\text { Interessadas } \\
\text { - Abrangência das Divulgações } \\
\text { Sociais }\end{array}$ & $\begin{array}{l}\text { Ciocirlan e Pettersson (2012) } \\
\text { Fodio e Oba (2012) } \\
\text { Rao et al. (2012) } \\
\text { Frias-Aceituno et al. (2013) } \\
\text { Setó-Pamies (2013) } \\
\text { Fernandez-Feijoo et al. (2014) } \\
\text { Liao et al. (2014) } \\
\text { Ben-Amar et al. (2015) }\end{array}$ \\
\hline
\end{tabular}




\section{Referências.}

ABBOTT, L., PARKER, S., PRESLEY, T. (2012). Female Board Presence and the Likelihood of Financial Restatement. Accounting Horizons 26(4), 607-629.

ADAMS, R., FUNK, P. (2012). Beyond the glass ceiling: Does gender matter? Management Science, 58(2), 219-235.

AGARS, M. D. (2004). Reconsidering the impact of gender stereotypes on the advancement of women in organizations. Psychology of Women Quarterly, 28, 103-111.

AGUILERA, R., JACKSON, G. (2003). The cross-national diversity of corporate governance: Dimensions and determinants, Academy of Management Journal, 28: 447-465.

AKAAH, I. P. (1989). Differences in research ethics judgments between male and female. Journal of Business Ethics, 8(5), 375-381.

ARLOW, P. (1991). Personal characteristics in college students' evaluations of business ethics and corporate social responsibility. Journal of Business Ethics, 10: 63-69.

BACKHAUS, K. B., STONE, B. A., HEINER, K. (2002). Exploring the relationship between corporate social performance and employer attractiveness. Business \& Society, 41(3), 292-318.

BAUMAN, C. W., SKITKA, L. J. (2012). Corporate social responsibility as a source of employee satisfaction. Research in Organizational Behavior, 32, 63-86.

BASELGA-PASCUAL, L., TRUJILLO-PONCE, A., VÄHÄMAA, E., VÄHÄMAA, S. (2014). Ethical Reputation of Financial Institutions: Do Board Characteristics Matter? Journal of Business Ethics, 1-22. BEAR, S., RAHMAN, N., POST, C. (2010). The impact of board diversity and gender composition on corporate social responsibility and firm reputation. Journal of Business Ethics, 97, 207-221.

BEN-AMAR, W., CHANG, M., \& MCILKENNY, P. (2015). Board gender diversity and corporate response to sustainability initiatives: Evidence from the carbon disclosure project. Journal of Business Ethics, 1-15.

BERNARDI, R., BOSCO, S., \& VASSILL, K. (2006). Does female representation on boards of directors associate with fortune's 100 'best companies' list? Business and Society, 45, 235-248.

BERNARDI, R., ARNOLD, D. (1997), “An examination of moral development within public accounting by gender, staff level, and firm", Contemporary Accounting Research, Vol. 14 No. 4, pp. 653-668.

BETZ, M., O'CONNELL, L. SHEPARD, J. (1989), “Gender differences in proclivity for unethical behavior", Journal of Business Ethics, Vol. 8 No. 5, pp. 321-324.

BEUTEL, A., MARINI, M. (1995). Gender and Values. American Sociological Review 60:436-48.

BIAN, Lin, LESLIE, Sarah-Jane, CIMPIAN, Andrei (2017). Gender stereotypes about intellectual ability emerge early and influence children's interests. Science 355, 389-391.

BILIMORIA, D., PIDERIT, S. (1994) Board committee membership: Effects of sex-based bias, Academy of Management Journal, 37(6):1453-77.

BLAZOVICH, J. L., SMITH, L. M. (2011). Ethical corporate citizenship: Does it pay? Research on Professional Responsibility and Ethics in Accounting, 15, 127-163.

BORKOWSKI, S. C., UGRAS, Y. J. (1998). Business students and ethics: A meta-analysis. journal of Business Ethics, 17(11), 1117-1127.

BOULOUTA, I. (2013). Hidden Connections: The Link Between Board Gender Diversity and Corporate Social Performance. Journal of Business Ethics. 113: 185-197. 
BRAMMER, S., MILLINGTON, A., \& PAVELIN, S. (2009). Corporate reputation and women on the board. British Journal of Management, 20(1): 17-29.

BURGESS, Z., THARENOU, P. (2002). Women board directors: Characteristics of the few. Journal of Business Ethics, 37(1), 39-49.

BURGESS, Z., FALLON, B. 2003. A longitudinal study of women directors in Australia, Women in Management Review, 18: 359-368.

BYRON, K., POST, C. (2016). Women on Board of Directors and Corporate Social Performance: AMetaAnalysis. Corporate Governance: An International Review. Forthcoming. DOI: 10.1111/corg.12165

CARLSON, R. (1972). Understanding women: Implications for personality theory and research. Journal of Social Issues, 28: 17-32.

CARROLL, A. B. (1999). Corporate social responsibility: Evolution of a definitional construct, Business \& Society, 38: 268-95.

CHOI, T. H., JUNG, J. (2008). Ethical commitment, financial performance, and valuation: An empirical investigation of Korean companies. Journal of Business Ethics, 81, 447-463.

CIOCIRLAN, C., PETTERSSON, C. (2012). Does workforce diversity matter in the fight against climate change? An analysis of fortune 500 companies. Corporate Social Responsibility and Environmental Management, 19, 47-62.

CUMMING, D., LEUNG, T., RUI, O. (2012). Gender diversity and securities fraud. Working paper available at http://dx.doi.org/10.2139/ssrn.2154934

DALTON, D. R., DALTON, C. M. (2010). Women and corporate boards of directors: The promise of increased, and substantive, participation in the post Sarbanes-Oxley era, Business Horizons, 53: 257268.

DAILY, C. M., CERTO, S. T., DALTON, D. R. (2000). The future of corporate women: Progress toward the executive suite and the boardroom? In R. J. Burke \& M. C. Mattis (Eds.), Women on corporate boards of directors: International challenges and opportunities (pp. 11-23). The Netherlands: Kluwer Academic Publishers.

DAVIDSON, D., FREUDENBURG, W. (1996). Gender and environmental risk concerns: A review and analysis of available literature. Environment and Behavior, 28(3), 302-339.

DAWSON, L. M. (1997). Ethical differences between men and women in the sales profession. Journal of Business Ethics, 16: 1143-1152.

DIAMANTOPOULOS, A., SCHLEGELMILCH, B., SINKOVICS, R., BOHLEN, G. (2003). Can socio-demographics still play a role in profiling green consumers? A review of the evidence and an empirical investigation. Journal of Business Research 56: 465-480.

DONKER, H., POFF, D., ZAHIR, S. (2008). Corporate values, codes of ethics, and firm performance: A look at the Canadian context. Journal of Business Ethics, 82, 527-537.

EAGLY, A. (2009). The his and hers of prosocial behavior: An examination of the social psychology of gender. American Psychologist, 64, 644-658.

,CARLI, L. (2007). Through the labyrinth: The truth about how women become leaders. Boston: Harvard Business Press.

KARAU, S. (2002). Role congruity theory of prejudice toward female leaders. Psychological Review, 109, 573-598. 
, KARAU, S., MAKHIJANI, M. (1995). Gender and the effectiveness of leaders: A metaanalysis. Psychological Bulletin, 117: 125-145.

, JOHNSON, B. (1990). Gender and leadership style: A meta-analysis. Psychological Bulletin, 108: 233-256.

, JOHANNESEN-SCHMIDT, M., VAN ENGEN, M. (2003). Transformational, transactional, and laissez-faire leadership styles: A meta-analysis comparing women and men. Psychological Bulletin, 129(4), 569-591.

EISENBERG, N., MILLER, P. A. (1987). Empathy and prosocial behavior. Psychological Bulletin, 101, 91-119.

FERNANDEZ-FEIJOO, B., ROMERO, S., RUIZ-BLANCO, S. (2014). Women on boards: Do they affect sustainability reporting? Corporate Social Responsibility and Environmental Management, 21: 351-64.

FERRELL, O. C., SKINNER, J. S. (1988). Ethical behavior and bureaucratic structure in marketing research organizations. Journal of Marketing Research, 25, 103-109.

FINKELSTEIN, S. (1992). Power in top management teams: Dimensions, measurement, and validation, Academy of Management Journal, 35: 505-538.

, MOONEY, A. C. (2003). Not the usual suspects: How to use board process to make boards better, Academy of Management Perspectives, 17: 101-113.

FISCHER, K., KHOURY, N. (2007). The impact of ethical ratings on Canadian security performance: Portfolio management and corporate governance implications. The Quarterly Review of Economics and Finance, 47, 40-54.

FODIO, M. I., OBA, V. C. (2012). Boards' gender mix and extent of environmental responsibility information disclosure in Nigeria: An empirical study. European Journal of Business and Management, 4(14), 163-169.

FRIAS-ACEITUNO, J. V., RODRIGUEZ-ARIZA, L., \& GARCIA-SÁNCHEZ, I. M. (2013). The role of the board in the dissemination of integrated corporate social reporting. Corporate Social Responsibility and Environmental Management, 20: 219-33.

GALASKIEWICZ, J. (1991). Making corporate actors accountable: Institution-building in MinneapolisSt. Paul. In W. W. Powell \& P. J. DiMaggio (Eds.), The new institutionalism in organizational analysis. Chicago: University of Chicago Press.

GARCIA-SANCHEZ, I., RODRIGUEZ-DOMINGUEZ, L., FRIAS-ACEITUNO, J. (2015). Board of directors and ethics codes in different corporate governance systems. Journal of Business Ethics. 131: 681-698.

GILLIGAN, C. (1982). In a different voice: Psychological theory and women's development. Cambridge, MA: Harvard University Press.

GLASS, C., COOK, A., INGERSOLL, A. R. (2015). Do women leaders promote sustainability? Analyzing the effect of corporate governance composition on environmental performance, Business Strategy and the Environment. DOI:10.1002/bse.1879.

GLICK, P., FISKE, S. T. (1999). Gender, power dynamics, and social interaction. In M. M. Ferree, J. Lorber and B. B. Hess (Eds.), Revisioning gender, Vol. 5: 365-398. Oxford, England: AltaMira Press.

GROYSBERG, B., BELL, D. (2013). Dysfunction in the boardroom. Harvard Business Review, 91(6), 89-97. 
GUL, F., SRINIDHI, B., \& NG, A. (2011). Does board gender diversity improve the informativeness of stock prices? Journal of Accounting and Economics. 51: 314-338.

GUTEK, B. A., MORASCH, B. (1982). Sex ratios, sex-role spillover and sexual harassment of women at work. Journal of Social Issues, 38, 55-74.

HAFSI, T., TURGUT, G. (2013). Boardroom diversity and its effect on social performance: Conceptualization and empirical evidence. Journal of Business Ethics, 112(3), 463-479.

HATCH, C., STEPHEN, S. (2015). Gender Effects on Perceptions of Individual and Corporate Social Responsibility. Journal of Applied Business and Economics. 17(3): 63-71.

HARRIGAN, K. R. (1981). Numbers and positions of women elected to corporate boards, Academy of Management Journal, 24: 619-625.

HEILMAN, M., CHEN, J. (2005). Same behavior, different consequences: Reactions to men's and women's altruistic citizenship behavior. Journal of Applied Psychology, 90, 431-441.

HILLMAN, A. (2015). Board diversity: Beginning to unpeel the onion. Corporate Governance: An International Review. 23(2): 104-107.

HILLMAN, A. J., CANNELLA, A. A., Jr., HARRIS, I. C. (2002). Women and racial minorities in the boardroom: How do directors differ? Journal of Management, 28: 747-763.

HO, S., LI, A., TAM, K., ZHANG, F. (2015). CEO Gender, Ethical Leadership, and Accounting Conservatism. Journal of Business Ethics. 127: 351-370.

IBRAHIM, N., ANGELIDIS, J. (2009). The relative importance of ethics as a selection criterion for entry-level public accountants: Does gender make a difference? Journal of Business Ethics, 85, 49-58.

ISIDRO, H., SOBRAL, M. (2015).The Effects of Women on Corporate Boards on Firm Value, Financial Performance and Ethical and Social Compliance. Journal of Business Ethics. 132: 1-19.

JAIN, T., JAMALI, D. (2016). Looking Inside the Black Box: The Effect of Corporate Governance on Corporate Social Responsibility. Corporate Governance. Forthcoming. DOI:10.1111/corg.12154.

JAFFEE, S., HYDE, S. (2000). Gender differences in moral orientation: A meta-analysis. Psychological Bulletin, 126(5), 703-726.

KANSAKU, K., YAMAURA, A., KITAZAWA, S. (2000). Sex differences in lateralization revealed in the posterior language areas. Cerebral Cortex, 10: 866-872.

KODINSKY, R., TIMOTHY M., DANIEL S., HENKEL, E. (2010). Attitudes about Corporate Social Responsibility: Business Student Predictors. Journal of Business Ethics 91:167-81.

KOHLBERG, L. (1981). The philosophy of moral development moral stages and the idea of justice. Harper \& Row.

KONRAD, A. M., KRAMER, V., ERKUT, S. (2008) Critical mass: The impact of three or more women on corporate boards, Organizational Dynamics, 37(2): 145-64.

KRISHNAN, G., PARSONS, L. (2008). Getting to the Bottom Line: An Exploration of Gender and Earnings Quality. Journal of Business Ethics 78, 65-76.

LA TAILLE, Y. de. (2002). Vergonha, a ferida moral. 2. ed. Petrópolis: Vozes.

LABELLE, R., GARGOURI, R., \& FRANCOEUR, C. (2010). Ethics, diversity management, and financial reporting quality. Journal of Business Ethics, 93(2), 335-353.

LIAO, L., LUO, L., TANG, Q. (2014). Gender diversity, board independence, environmental committee and greenhouse gas disclosure. British Accounting Review. 49: 409-424. 
LOE, T., FERRELL, L., MANSFIELD, P. (2000). A Review of Empirical Studies Assessing Ethical Decision Making in Business. Journal of Business Ethics 25:185-204.

LU, W., CHAU, K. W., WANG, H., PAN, W. (2014). A decade's debate on the nexus between corporate social and corporate financial performance: a critical review of empirical studies 2002-2011. Journal of Cleaner Production, 79, 195-206.

LUND, D. B. (2008). Gender differences in ethics judgment of marketing professionals in the United States. Journal of Business Ethics, 77(4), 501-515.

MAINIERI, T., BARNETT, E., VALDERO, T., UNIPAN, J., OSKAMP, S. (1997), “Green buying: The influence of environmental concern on consumer behavior", The Journal of Social Psychology, Vol. 137 No. 2, pp. 189-204.

MALLIN, C., MICHELON, G. (2011). Board reputation attributes and corporate social performance: An empirical investigation of the U.S. Best Corporate Citizens. Accounting and Business Research, 41(2), 119-144.

MARQUIS, C., LEE, M. (2013). Who is governing whom? Executives, governance, and the structure of generosity in large U.S. firms. Strategic Management Journal, 34(4), 483-497.

MASON, E. S., MUDRACK, P. E. (1996). Gender and ethical orientation: A test of gender and occupational socialization theories. Journal of Business Ethics, 15: 599-604.

MATTINGLY, J.E., BERMAN S.L. (2006). Measurement of corporate social action. Business \& Society 45(1): 20-46.

MCKINSEY \& COMPANY (2013). Women Matter 2013: gender diversity in top management: moving corporate culture, moving boundaries.

MIETHE, T. D., ROTHSCHILD, J. (1994). Whistleblowing and the control of organizational misconduct. Sociological Inquiry, 643(3), 322-347.

NIELSEN, S., HUSE, M. (2010). The contribution of women on boards of directors: Going beyond the surface. Corporate Governance: An International Review, 18(2), 136-148.

O'FALLON, M., BUTTERFIELD, K. (2005). A Review of the Empirical Ethical Decision-Making Literature: 1996-2003. Journal of Business Ethics 59:375-413.

PELLED, L. H., EISENHARDT, K. M., XIN, K. R. (1999). Exploring the black box: An analysis of work group diversity, conflict, and performance. Administrative Science Quarterly, 44(1), 1-28.

PETERSON, C., PHILPOT, J. (2007). Women's roles on U.S. Fortune 500 boards: Director expertise and committee memberships. Journal of Business Ethics, 72(2), 177-196.

PERSONS, O. (2015). Corporate Governance Characteristics of Most Admired Companies. International Journal of Business and Social Science. 6(3): 11-18.

POST, C., RAHMAN, N., RUBOW, E. (2011). Green governance: Boards' of directors composition and environmental corporate social responsibility. Business and Society, 50(1), 189-223.

POST, C., BYRON, K. (2015). Women on boards and firm financial performance: A meta-analysis. Academy of Management Journal, 58(5), 1546-1571.

POST, C., RAHMAN, N., MCQUILlEN, C. (2015). From Board Composition to Corporate Environmental Performance Through Sustainability-Themed Alliances. Journal of Business Ethics. 130:423-435. 
RAO, K. K., TILT, C. A., LESTER, L. H. (2012). Corporate governance and environmental reporting: An Australian study. Corporate Governance, 12(2), 143-163.

RAGINS, B., SUNDSTROM, E. (1989). Gender and power in organizations: A longitudinal perspective, Psychological Bulletin, 105: 51-88.

RAYTON, B. A., BRAMMER, S. J., MILLINGTON, A. I. (2015). Corporate social performance and the psychological contract. Group \& Organization Management, 40(3), 353-377.

REUBEN, E., SAPIENZA, P., ZINGALES, L. (2014). How stereotypes impair women's careers in science. Proceedings of the National Academy of Sciences, 111(12), 4403-4408.

REUBEN, E., REY-BIEL, P., SAPIENZA, P., ZINGALES, L. (2012). The emergence of male leadership in competitive environments. Journal of Economic Behavior \& Organization, 83(1), 111-117.

RIDGEWAY, C. L. 2001. The emergence of status beliefs: From structural inequality to legitimizing ideology. In J. T. Jost and B. Major (Eds.), The psychology of legitimacy: Emerging perspectives on ideology, justice, and intergroup relation: 257-277. Cambridge, MA: Cambridge University Press.

(2009). Framed before we know it: How gender shapes social relations, Gender \& Society, 23: $145-160$.

SMITH-LOVIN, L. (1999). The gender system and interaction, Annual Review of Sociology, 25: 191-126.

ROSE, C. (2007). Does female board representation influence firm performance? The danish evidence. Corporate Governance, 15(2), 404-413.

ROTHSCHILD, J., MIETHE, T. D. (1999). Whistle-blower disclosures and management retaliation: The battle to control information about organizational corruption. Work \& Occupations, 26(1), 107-128.

RUDMAN, L. A., GLICK, P. (2001). Prescriptive gender stereotypes and backlash toward agentic women. Journal of Social Issues, 57(4), 743-762.

RUDMAN, L. A., GLICK, P. (2012). Social psychology of gender. New York: Guilford Press.

RYAN, M., HASLAM, S. (2005) The glass cliff: Evidence that women are over-represented in precarious leadership positions, British Journal of Management, 16: 81-90.

SANDBERG, Sheryl. Lean In: women, work and the will to lead. US: Alfred A. Knopf, 2013.

SEIERSTAD, C. (2015). Beyond the Business Case: The Need for Both Utility and Justice Rationales for Increasing the Share of Women on Boards. Corporate Governance: An International Review. 23: 1-16.

SETÓ-PAMIES, D. (2013). The relationship between women directors and corporate social responsibility. Corporate Social Responsibility and Environmental Management. 22: 334-345.

SCARLAT, E., SHIELDS, K., CLACHER, I. (2015). CEO and CFO Gender, Corporate Culture and FirmWide Insider Trading. Working paper available at $\mathrm{http} / / / \mathrm{www} . e c o n . u p f . e d u /$ docs/seminars/scarlat.pdf SHRADER, C., BLACKBURN, V., ILES, P. (1997) Women in management and firm value: An exploratory study, Journal of Managerial Issues, 9: 355-72.

SILVEIRA, A. M., DONAGGIO, A. R. F., SICA, L. P. P. P, RAMOS, L. O. (2013). Women's participation in senior management positions: gender social relations, law and corporate governance. Disponível em: https://papers.ssrn.com/sol3/papers.cfm?abstract_id=2508929.

SIMGA-MUGAN, C., DALY, B. A., ONKAL, D., KAVUT, L. (2005). The influence of nationality and gender on ethical sensitivity: An application of the issue-contingent model. Journal of Business Ethics, 57(2), 139-159. 
SLOTE, M. (2007). The ethics of care and empathy. New York: Routledge.

SINGH, V., TERJESEN, S., VINNICOMBE, S. (2008). Newly appointed directors in the boardroom: How do women and men differ. European Management Journal. 26(1): 48-58.

SRINIDHI, B., GUL, F., TSUI, J. (2011). Female directors and earnings quality. Contemporary Accounting Research, 28(5), 1610-1644.

STEFFENSMEIER, D., SCHWARTZ, J., ROCHE, M. (2013). Gender and Twenty-First-Century Corporate Crime: Female Involvement and the Gender Gap in Enron-Era Corporate Frauds. American Sociological Review. 78(3): 448-476.

STURMER, S., SNYDER, M., OMOTO, A. M. (2005). Prosocial emotions and helping: The moderating role of group membership. Journal of Personality and Social Psychology, 88(3), 532-546.

SUNDARASEN, S., JE-YEN T., RAJANGAM, N. (2016). Board Composition and Corporate Social Responsibility in an Emerging Market. Corporate Governance. 16(1): 35-53. DOI 10.1108/CG-052015-0059

TERJESEN, S., SEALY, R. SINGH, V. (2009). Women directors on corporate boards: A review and research agenda. Corporate Governance: An International Review. 17: 320-337.

THE CORPORATE GENDER GAP REPORT. World Economic Forum, Genebra, 2010.

TORCHIA, M., CALABRÒ, A., HUSE, M. (2011). Women directors on corporate boards: From tokenism to critical mass. Journal of Business Ethics, 102: 299-317.

VALENTINE, S. R., RITTENBURG, T. L. (2004). Spanish and American business professionals' ethical evaluations in global situations. Journal of Business Ethics, 51(1), 1-14.

VERMEIR, I., VAN KENHOVE, P. (2008). Gender differences in double standards. Journal of Business Ethics, 81(2), 281-295.

WALLS, J., BERRONE, P., PHAN, P. (2012). Corporate governance and environmental performance: Is there really a link? Strategic Management Journal, 33: 885-913.

WEEKS, W. A., MOORE, C. W., MCKINNEY, J. A., LONGENECKER, J. G. (1999). The effects of gender and career stage on ethical judgment. Journal of Business Ethics, 20(4), 301-313.

WEBB, E. (2004). An examination of socially responsible firms' board structure. Journal of Management and Governance, 8(3), 255-277.

WILLIAMS, R. (2003). Women on corporate boards of directors and their influence on corporate philanthropy. Journal of Business Ethics, 42(1): 1-10.

WOOD, D. J. (1991). Corporate social performance revisited. Academy of Management Review, 16, 691-718.

(2010). Measuring corporate social performance: A review, International Journal of Management Reviews, 12: 50-84.

EAGLY, A. H. (2009). Gender identity. In M. R. Leary \& R. H. Hoyle (Eds.), Handbook of individual differences in social behavior (pp. 109-125). New York: Guilford Press.

WORLD BANK GROUP (2015). Women, Business and the Law 2016: Getting to Equal. Washington, DC: World Bank.

WRIGHT, E. O., BAXTER, J., BIRKELUND, G. E. 1995. The gender gap in workplace authority: A cross-national study, American Sociological Review, 60: 407-435.

ZELECHOWSKI, D., BILIMORIA, D. (2006). Characteristics of CEOs and boards with women inside 
directors. Corporate Board: Roles, Duties and Composition, 2(2), 14-21.

ZHANG, L. (2012). Board demographic diversity, independence, and corporate social performance. Corporate Governance. 12: 686-700.

ZHANG, J., ZHU, H., DING, H. (2013). Board composition and corporate social responsibility: An empirical investigation in the post Sarbanes-Oxley era. Journal of Business Ethics, 114(3), 381-392.

\section{SOBRE O AUTOR:}

\section{Alexandre di Miceli da Silveira}

Prof. Dr. Alexandre Di Miceli da Silveira é palestrante internacional, consultor, professor, pesquisador e articulista dedicado integralmente à governança corporativa e ética empresarial desde 2000. É doutor e mestre em Administração de Empresas pela FEA-USP, com pós-doutorados pelas Universidades de Louvain (Bélgica) e Cornell (Estados Unidos), e temporada na Universidade de Harvard em 2015.

Professor do Mestrado da Fecsp, Fundador da Direzione Consultoria e Educação Executiva, é autor dos principais livros-texto sobre ética empresarial e governança no país, incluindo "The Virtuous Barrel: How to Transform Corporate

Scandals into Good Businesses via Behavioral Ethics", "Ética Empresarial na Prática: Soluções para a Governança e Gestão no Século XXI”, “Governança Corporativa no Brasil e no Mundo" (finalista do Prêmio Jabuti 2010) e "Governança Corporativa: o Essencial para Líderes".

É consultor e palestrante da International Finance Corporation (IFC, membro do Grupo Banco Mundial) em projetos internacionais relacionados à ética, gestão e governança, e é Professor dos cursos para Conselheiros de Administração do

IBGC desde 2005.

Foi consultor da OCDE, professor da USP durante dez anos e vice-presidente da Sociedade Brasileira de Finanças. Autor de mais de 50 trabalhos científicos sobre governança, foi agraciado com dezenas de prêmios, incluindo o Prêmio

"Personalidade do Ano" 2018 concedido pela Associação Brasileira de Treinamento e Desenvolvimento do Paraná, prêmios IBGC Academia nos anos de 2014, 2013, 2011, 2009 e 2003, e o Revelação em Finanças do IBEF 2006. 


\section{SOBRE A AUTORA:}

\section{Angela Rita Franco Donaggio}

Doutora em Direito Comercial pela Universidade de São Paulo (FD-USP), aprovada cum laude, Mestra em Direito dos Negócios e Desenvolvimento Econômico e Social por FGV Direito SP e Bacharela em Direito pela Pontifícia Universidade Católica de São Paulo (PUC-SP). Visiting Researcher em Harvard Law School e Visiting Professor em Cornell Law School.

Professora do curso para conselheiros de administração do Instituto Brasileiro de Governança Corporativa (IBGC) e professora de pós-graduação da FGV e da FACAMP. Pesquisadora da FGV Direito SP e integrante do Grupo de Estudos em Direito, Gênero e Identidade. Professora Assistente em Direito Comercial (PAE) da Universidade de São Paulo - USP (2013).

Em 2014 ganhou o Prêmio IBGC Itaú Academia. Em 2013 ganhou o $9^{\circ}$ Prêmio ANBIMA-Casa das Garças de Mercado de Capitais como melhor projeto de tese de doutorado (ANBIMA/IEPE/CdG). Entre 2009 e 2011 foi pesquisadora-bolsista da Direito GV, recebendo por duas vezes a Bolsa-mérito Mario Henrique Simonsen concedida devido a excepcional desempenho acadêmico, potencial para inovação científica e contribuição efetiva para com as atividades acadêmicas da DIREITO GV.

Autora da tese "Regulação e Autorregulação no Mercado de Valores Mobiliários:

O caso dos segmentos especiais de listagem da BM\&FBovespa" (2016) e do livro “Governança Corporativa e Novo Mercado: Proteção ao investidor e falhas no marcoregulatório" (Saraiva, 2012).

Coautora dos livros: "A Sociedade Anônima e a Democracia na América do Sul: Regulação e Governança Corporativa" (FGV Direito SP, 2016); "Estado, Empresa e

Liberdade: Textos em homenagem ao Professor Antonio Angarita” (Quartier Latin, 2016); "A Regulação Brasileira do Mercado de Capitais" (Saraiva, 2015); "Mercado de capitais Brasileiro II - Doutrina, Cases \& Materiais" (Quartier Latin, 2015); “Corporate

Governance in Emerging Markets" (Springer, 2014); "Governança Corporativa e Ofertas Públicas Iniciais no Brasil” (Direito GV, 2013); "Estado e empresa: uma relação imbricada" (Direito GV, 2013); "Empresas Familiares: Governança Corporativa, Governança Familiar e Governança Jurídica" (Saraiva, 2010); "Direito Societário: Estratégias Societárias, Planejamento Tributário e Sucessório" (Saraiva, 2009). Coautora do "Women in Business Leadership Boost ESG Performance: Existing

Body of Evidence Makes Compelling Case" (International Finance Corporation, 2019), do "Modelo de Regimento Interno do Conselho de Administração do IBGC" (IBGC, 2008) e do "OECD Country Report - The Role of Institutional Investors in Promoting Corporate Governance in Brazil” (OECD, 2007). 